\title{
The Diabetes Subgroup Baseline Characteristics of the Avoiding Cardiovascular Events Through Combination Therapy in Patients Living With Systolic Hypertension (ACCOMPLISH) Trial
}

D abetes mellitus (DM) is the most common cause of kidney failure and a major cause of cardiovascular morbidity and mortality. ${ }^{1}$ The Avoiding Cardiovascular Events Through Combination Therapy in Patients Living With Systolic Hypertension (ACCOMPLISH) trial examined cardiovascular outcomes in approximately 12,000 patients, many of whom have DM. A full description of the baseline data for the entire ACCOMPLISH trial as well as the methods and design of this trial have been published previously. ${ }^{2,3}$

Briefly, ACCOMPLISH is a randomized double-blind trial that compared the efficacy of one fixed-dose combination, amlodipine besylate/ benazepril, to that of another, benazepril/hydrochlorothiazide, in preventing fatal and nonfatal cardiovascular outcomes. $^{2}$ Patients randomized to study medications did not have a washout period. The study drug doses were force-titrated during the first 2 months of the trial to maximum angiotensinconverting enzyme inhibitor levels: amlodipine besylate/benazepril $5 / 40$ $\mathrm{mg}$ and benazepril/ hydrochlorothiazide $40 / 12.5 \mathrm{mg}$. Within the first 3 months, dose increases to $10 / 40 \mathrm{mg}$ or $40 / 25 \mathrm{mg}$, respectively, could occur to achieve blood pressure (BP) goals. If $\mathrm{BP}$ was still not at goal level, addition of other antihypertensive agents with the exception of the randomized drug classes could occur. These additional antihypertensive agents included $\beta$-blockers, $\alpha$-blockers, and clonidine, and, if needed, loop diuretics could be added in order to reach BP targets $(<140 / 90 \mathrm{~mm} \mathrm{Hg}$ for most patients and $<130 / 80 \mathrm{~mm} \mathrm{Hg}$ [suggested, but not mandated] for patients with DM

The Avoiding Cardiovascular Events Through Combination Therapy in Patients Living With Systolic Hypertension (ACCOMPLISH) trial is the first cardiovascular outcome trial designed to compare initial use of 2 different fixed-dose antihypertensive regimens, benazepril plus hydrochlorothiazide vs benazepril plus amlodipine, on cardiovascular end points in hypertensive patients at high cardiovascular risk secondary to previous major events or presence of diabetes mellitus (DM). Of the II,464 patients, $60.4 \%$ had DM. Compared with non-DM patients, DM patients were less likely to have previous myocardial infarctions (15\% vs $37 \%$ ) or strokes (8\% vs $21 \%$ ). Those with DM were more likely to be female ( $43 \%$ vs $34 \%$ ), black ( $15 \%$ vs $8 \%$ ), overweight (body mass index, 32 vs $29 \mathrm{~kg} / \mathrm{m}^{2}$ ). At baseline, DM patients were more likely to have the metabolic syndrome, manifested by higher levels of fasting glucose (I $45 \mathrm{vs} 101 \mathrm{mg} / \mathrm{dL}$ ) and triglycerides (I 78 vs $150 \mathrm{mg} / \mathrm{dL}$ ) and slightly lower high-density lipoprotein cholesterol values (48 vs $5 \mathrm{I} \mathrm{mg/dL)}$ compared to the non-DM cohort. Although estimated glomerular filtration rate $\left(80 \mathrm{vs} 76 \mathrm{~mL} / \mathrm{min} / 1.73 \mathrm{~m}^{2}\right)$ was similar in the $D M$ and non-DM groups, presence of both albuminuria $(8.7 \%$ vs $3.5 \%)$ and microalbuminuria $(29 \%$ vs $20 \%$ ) were more prevalent in the DM group. After 6 months of treatment, blood pressure control rates $(<140 / 90 \mathrm{~mm} \mathrm{Hg})$ using blinded data (both therapeutic groups combined) for DM demonstrated that $42.8 \%$ of DM patients had blood pressure levels $<130 / 80 \mathrm{~mm} \mathrm{Hg}$. ACCOMPLISH will provide valuable guidance on optimizing treatment strategies in hypertensive patients at high cardiovascular risk with and without DM. J Cardiometab Syndr. 2008;3:229-233. ${ }^{\circledR} 2008$ Le Jacq

George Bakris, MD;' Allen Hester, PhD ${ }^{2}$ Michael Weber, MD; ${ }^{3}$ Bjorn Dahlof, MD; ${ }^{4}$ Bert Pitt, MD; ${ }^{5}$ Eric Velasquez, MD; ${ }^{6}$ Linda Staikos-Byrne, PhD ; Victor Shi, PhD; ${ }^{7}$ Ken Jamerson, MD; ${ }^{5}$ on behalf of the ACCOMPLISH Investigators From the Hypertensive Diseases Unit, Department of Medicine, University of Chicago School of Medicine, Chicago, IL;' Department of Biostatistics, Novartis Pharmaceuticals, East Hanover, NJ; ${ }^{2}$ Department of Medicine, SUNY Downstate, Brooklyn, NY; ${ }^{3}$ Department of Medicine, University of Goteborg, Goteborg, Sweden; ${ }^{4}$ Department of Medicine, University of Michigan, Ann Arbor, Ml;, Duke University Medical Center and Duke Clinical Research Institute, Durham, NC; ${ }^{6}$ and Novartis, East Hanover, NJ ${ }^{7}$

Address for correspondence:

George Bakris, MD, University of Chicago School of Medicine,

584 I South Maryland Avenue, MC I027, Chicago, IL 60637

E-mail: gbakris@gmail.com

Manuscript received January 6, 2008; revised January I8, 2008;

accepted January 3I, 2008

or renal insufficiency). After the initial 3 -month period, patients were seen at 6-month intervals thereafter until the end of the 5-year trial.
ACCOMPLISH is distinctly different from previously completed cardiovascular outcomes trials in that it was designed to not have differences in $\mathrm{BP}$ 
Table I. Baseline Characteristics of Patients in the Diabetes Mellitus (DM) and Non-DM Cohorts $(\mathrm{N}=11,464)$

\begin{tabular}{|lcc|}
\hline & $\begin{array}{c}\text { DM CoHort } \\
(\mathrm{N}=6924)\end{array}$ & $\begin{array}{c}\text { Non-DM CoHorT } \\
(\mathrm{N}=4540)\end{array}$ \\
\hline Male, \% & 57.3 & 66.0 \\
Female, \% & 42.7 & 34.0 \\
Mean age, $\mathrm{y}$ & 67.5 & 69.8 \\
Mean weight, $\mathrm{kg}$ & 91.8 & 83.7 \\
Mean height, $\mathrm{cm}$ & 168.8 & 169.8 \\
Mean body mass index, $\mathrm{kg} / \mathrm{m}^{2}$ & 32.2 & 29 \\
Race, \% & & \\
White & 80.1 & 89.7 \\
Black & 14.6 & 7.9 \\
Asian & 0.5 & 0.2 \\
Other & 4.8 & 2.2 \\
\hline
\end{tabular}

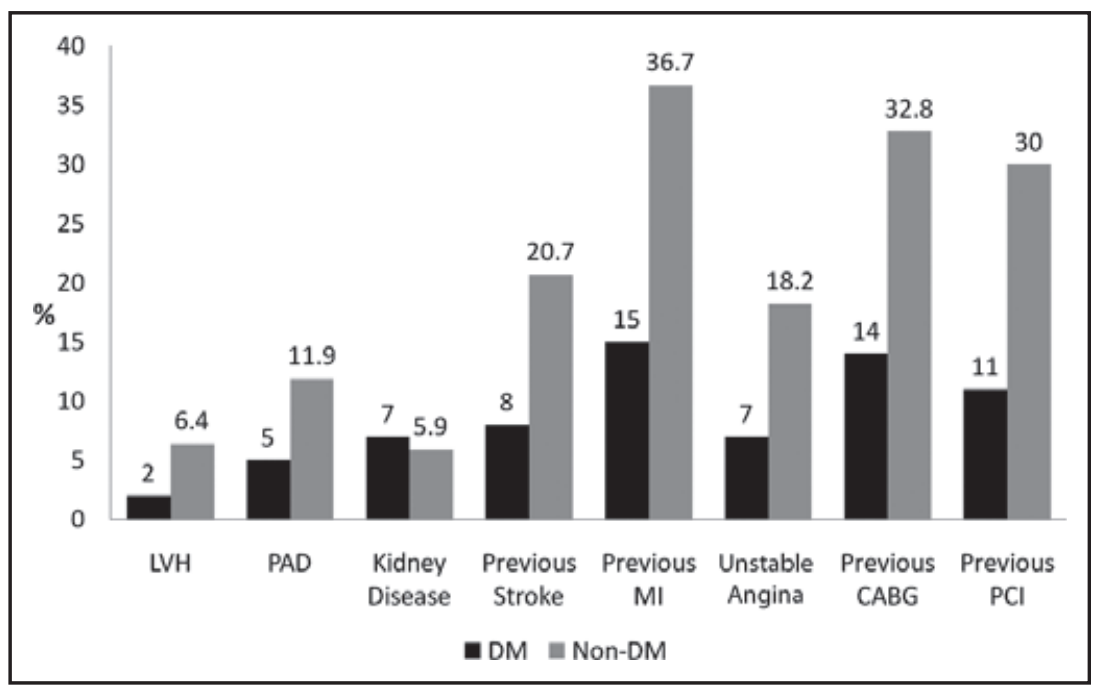

Figure 1. Baseline cardiovascular history comparing the cohorts with (DM) and without (non-DM) diabetes mellitus. $L V H$ indicates left ventricular hypertrophy; $P A D$, peripheral arterial disease; $M I$, myocardial infarction; $C A B G$, coronary artery bypass grafting; PCI, percutaneous coronary intervention.

within the first 6 to 12 months of the study. Previous trials like the Valsartan Antihypertensive Long-Term Use Evaluation (VALUE), the Anglo-Scandinavian Cardiac Outcomes Trial (ASCOT), and the Antihypertensive and Lipid-Lowering Treatment to Prevent Heart Attack Trial (ALLHAT) ${ }^{4-6}$ all had significant differences in BP within the first year of the trial, which affected the event rate early in VALUE. $^{7}$

The data in this report represent those of the cohort with DM and are based on all available BP observations at baseline (the beginning of the study treatment period immediately following randomization) and at 6 months. As of this writing, 11, 464 patients had BP data available for the present analysis. There is no discussion about the primary and other mortality/ morbidity end points in this report.

\section{Results}

Patient Characteristics. The inclusion and exclusion criteria for hypertensive patients at high cardiovascular risk have been described previously.,3 The baseline demographic distribution of patients with DM is shown in Table I. Note that the cohort with DM in this trial had fewer cardiovascular events at entry compared with other
Table II. Distribution of Patients With Diabetes Mellitus (DM) Throughout the Study Countries

\begin{tabular}{|lcc|}
\hline & $\begin{array}{c}\text { DM } \\
(\%)\end{array}$ & $\begin{array}{c}\text { No DM } \\
(\%)\end{array}$ \\
\hline Denmark $(\mathrm{n}=532)$ & 37.6 & 62.4 \\
Finland $(\mathrm{n}=587)$ & 62.5 & 37.5 \\
Norway $(\mathrm{n}=293)$ & 34.9 & 65.1 \\
Sweden $(\mathrm{n}=1942)$ & 55.6 & 44.4 \\
United States & 64.2 & 35.7 \\
$\quad(\mathrm{n}=8110)$ & & \\
Total $(\mathrm{N}=11,464)$ & 60.7 & 39.3 \\
\hline
\end{tabular}

clinical trials. The distribution of patients with DM between the United States and Scandinavia is shown in Table II. The distributions of cardiovascular events prior to randomization differed between those with and without DM, favoring fewer events in the DM cohort (Figure 1).

The previous antihypertensive medication history of the cohort is shown in Table III. Note that $4 \%$ of those with DM had nephropathy defined by either the presence of macroalbuminuria (urinary albumin excretion $>300 \mathrm{mg} / \mathrm{d}$ ) or an estimated glomerular filtration rate $<60 \mathrm{~mL} / \mathrm{min}$.

The baseline values for standard laboratory blood test results were similar in both the DM and non-DM cohorts, with the exception of values of fasting glucose and triglycerides and rates of albuminuria and microalbuminuria, which were all higher in DM patients (Table IV).

\section{Effects of Initial Combination} Therapy on BP. Baseline values of BP were measured before the initiation of study drugs, while patients were still receiving prestudy medications. Baseline $\mathrm{BP}$ values were similar across most subgroups, with the exception of the participants enrolled at the Nordic sites, where systolic BP values at the time of randomization were approximately $10 \mathrm{~mm} \mathrm{Hg}$ higher than in patients from the United States. The higher baseline BP level in the Nordic countries was due to local regulatory advice to only include patients in the trial whose BP was not controlled on their prestudy medications. In contrast, the United States investigators 
could enroll patients with either wellcontrolled or uncontrolled BP.

The mean BP for DM patients at study entry was $145.2 / 79.3 \mathrm{~mm} \mathrm{Hg}$. It was similar to those in the non-DM cohort: 145.4/80.0 mm Hg. At baseline, only $16 \%$ of DM patients had baseline BP values below the recommended goal level of $<130 / 80 \mathrm{~mm} \mathrm{Hg}$ (Figure 2). The effects of treatment on systolic BP after 6 months are shown in Figure 2.

Maximum Dose Plus Additional Antihypertensive Therapy. The study design required forced titration of the study drug to achieve BP goals; if goal levels were not achieved, add-on therapy with the aforementioned agents should be started. At 6 months, similar numbers of the cohort with and without DM were receiving maximally titrated doses of study medication $330.3 \%$ of the DM cohort vs $29.4 \%$ of the nonDM cohort). However, the number of patients requiring add-on medications differed: $16.9 \%$ in the DM group vs $10.6 \%$ in the non-DM group required 1 additional medication. Note that $8.9 \%$ of the DM cohort vs only $4.3 \%$ of the non-DM cohort required $>2$ additional antihypertensive medications to achieve BP goals in addition to maximally dosed study agents. The distribution of this add-on therapy by drug class is shown in Figure 3.

\section{Discussion}

ACCOMPLISH is the first trial to randomize 2 different fixed-dose combinations in a high-risk cohort to assess cardiovascular outcomes. The recommendation to initiate combination therapy in persons with stage 2 hypertension and in those with BP levels $\geq 20 / 10 \mathrm{~mm} \mathrm{Hg}$ above the their goal value was clear in the Seventh Report of the Joint National Committee on Prevention, Detection, Evaluation, and Treatment of High Blood Pressure (JNC 7). ${ }^{8}$ Thus, anyone who has DM and a $\mathrm{BP}$ of $\geq 150 / 90 \mathrm{~mm} \mathrm{Hg}$ should be started on 2 antihypertensive medications, 1 of which included a thiazidelike diuretic based on these guidelines. The DM cohort in the largest trial to

\begin{tabular}{|c|c|c|}
\hline & $\begin{array}{c}\text { DM COHORT } \\
(\mathrm{N}=6924)\end{array}$ & $\begin{array}{c}\text { Non-DM } \\
\text { Cohort }(4540)\end{array}$ \\
\hline No drug therapy & 0.5 & 0.9 \\
\hline ACE inhibitors & 56.7 & 46.1 \\
\hline $\mathrm{CCBs}$ & 35.9 & 37.8 \\
\hline $\mathrm{ARBs}$ & 28.1 & 23.1 \\
\hline Thiazide/thiazide-like diuretics & 38.7 & 35.2 \\
\hline Aldosterone receptor blockers & 1.6 & 1.4 \\
\hline$\beta$-Blockers & 40.6 & 58.1 \\
\hline$\alpha$-Blockers & 8.4 & 7.9 \\
\hline Loop diuretics & 13.9 & 10.0 \\
\hline Clonidine or clonidine-like agents & 3.2 & 2.5 \\
\hline Oral hypoglycemics and insulin sensitizers & 65.0 & 0.2 \\
\hline Insulin & 21.7 & 0 \\
\hline
\end{tabular}

Table IV. Selected Mean Laboratory Values at Baseline for DM and Non-DM Cohorts

\begin{tabular}{|lcc|}
\hline & $\begin{array}{c}\text { DM CoHorT } \\
(\mathrm{N}=6924)\end{array}$ & $\begin{array}{c}\text { Non-DM CoHoRT } \\
(4540)\end{array}$ \\
\hline Metabolic & & 101 \\
$\quad$ Fasting plasma glucose, mg/dL & 144.5 & 184 \\
Lipids & 184.6 & 51.4 \\
$\quad$ Total cholesterol, mg/dL & 48.3 & 102.4 \\
HDL cholesterol, mg/dL & 101.1 & 149.7 \\
LDL cholesterol, mg/dL & 178 & 76.3 \\
Triglycerides, mg/dL & & 1.0 \\
Kidney function & 80.4 & 3.5 \\
eGFR, mL/min/1.73 m ${ }^{2}$ & 0.9 & 20.3 \\
Serum creatinine, mg/dL & 8.7 & \\
Macroalbuminuria, \% (urinary & & \\
$\quad$ albumin excretion $>300$ mg/dL) & 29.3 & \\
Microalbuminuria, \% (urinary & & \\
albumin excretion 30-300 mg/dL) & \\
\hline Abbreviations: DM, diabetes mellitus; eGFR, estimated glomerular filtration rate; \\
HDL, high-density lipoprotein; LDL, low-density lipoprotein.
\end{tabular}

date, ALLHAT, found that diuretic treatment should be included as a part of the initial therapy for BP.? ACCOMPLISH will provide further information in a different setting (ie, pairing a thiazide diuretic with a blocker of the renin-angiotensin system) as to whether this should be the case to reduce cardiovascular outcomes. While both trials have a large group of patients with DM, one major difference is that achievement of a BP goal of $<130 / 80$ $\mathrm{mm} \mathrm{Hg}$ occurred much earlier (at 6 months) in the ACCOMPLISH trial compared to in ALLHAT, where it took much longer. ${ }^{6,9}$ This difference in total BP load may yield ultimately different cardiovascular outcomes. This was certainly the case in VALUE. ${ }^{7}$ This trial, along with the early large differences in $\mathrm{BP}$ values between groups receiving monotherapy in ALLHAT and ASCOT, may have also contributed to differences in those trial outcomes.

It is known that those with predominant systolic hypertension, such as the elderly, as well as those with DM are more likely to require a higher number of antihypertensive medications to achieve BP goals. ${ }^{10}$ The Intervention as a Goal in Hypertension Treatment (INSIGHT) trial in elderly individuals with predominant systolic hypertension mandated a relatively higher 


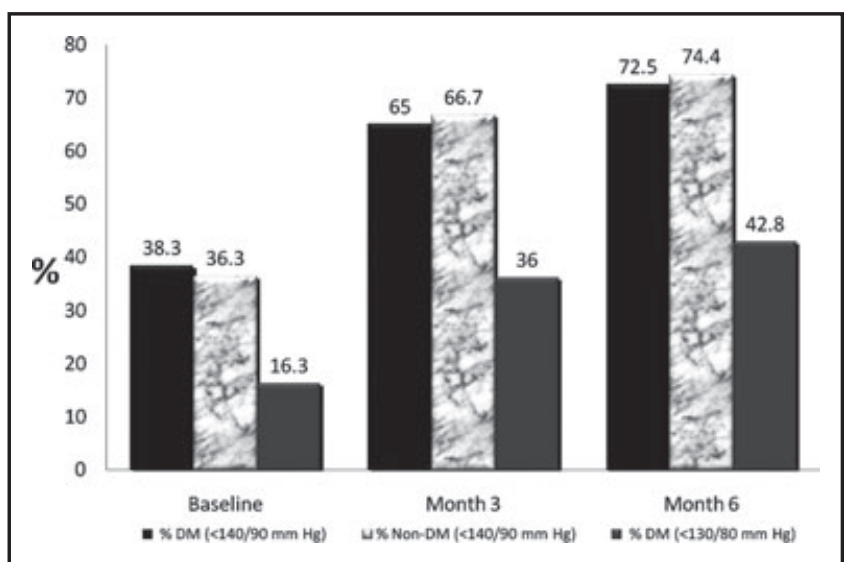

Figure 2. Percentages of patients with blood pressure at goal level at baseline and at 6 months in the diabetes mellitus (DM) and non-DM cohort.

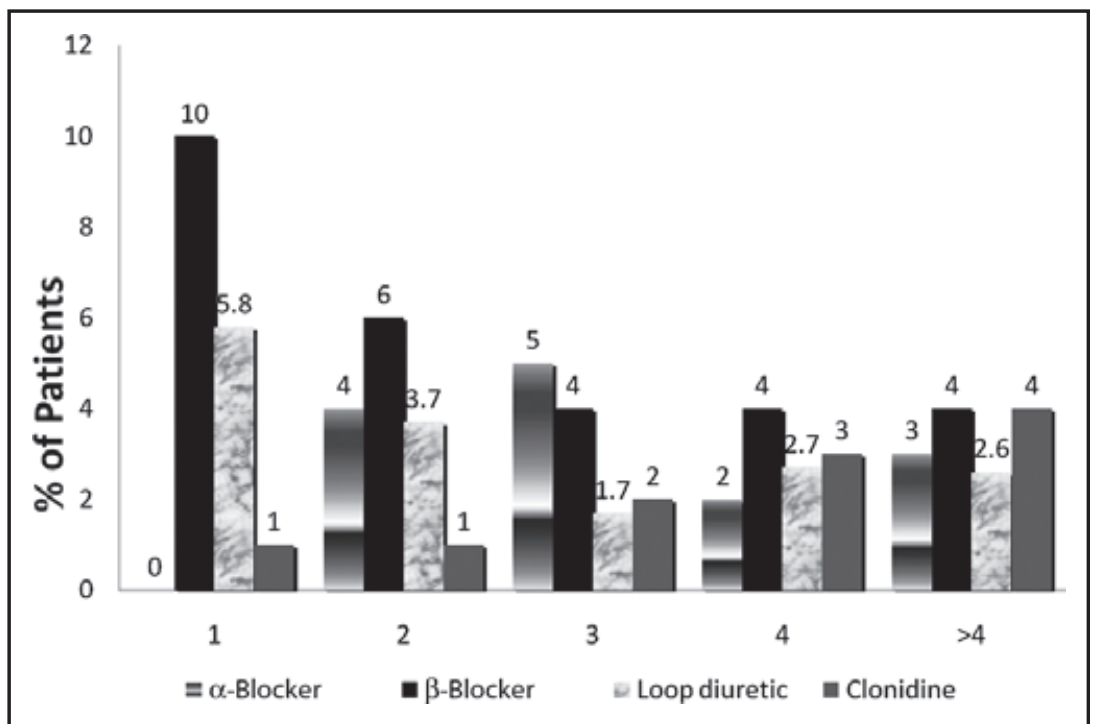

Figure 3. Percentages of patients with diabetes mellitus requiring add-on therapy and type of agents added.

number of antihypertensive medications in the cohort with DM to achieve BP goals. ${ }^{11}$ In ACCOMPLISH, our cohort with DM did not have predominant systolic hypertension but did require a higher number of antihypertensive medications compared with the nondiabetic cohort to achieve the $\mathrm{BP}$ goal.

The hope is that ACCOMPLISH, with its initial treatment using fixeddose combination therapy, will not result in this large early BP differential and thus will provide a better representation as to whether diuretics should be agents used early in the paired therapies to treat persons with DM.

Better BP control in ACCOMPLISH is evinced by the fact that the BP goal of $<130 / 80 \mathrm{~mm} \mathrm{Hg}$ was reached in $>43 \%$ of patients with DM within the first 6 months of the trial. Moreover, the BP goal of $<140 / 90 \mathrm{~mm} \mathrm{Hg}$ was achieved in $>72 \%$ by this time, a far better percentage than in any previous clinical trial. ${ }^{12}$

More than half of the randomized patients in the ACCOMPLISH trial had DM at study entry. In comparison to the non-DM patients, DM patients were more likely to be overweight, female, and black. More DM patients than non-DM patients had kidney disease and higher triglyceride levels and were previously treated with an angiotensin-converting enzyme inhibitor or an angiotensin receptor blocker. While there were similar levels of baseline BP present between the DM and non-DM cohort, only $16 \%$ of DM patients had $\mathrm{BP}$ that was at the recommended goal at study entry $(<130 / 80 \mathrm{~mm} \mathrm{Hg})$. This percentage improved to $43 \%$ following 6 months of participation in the trial. Moreover, a higher percentage of DM patients required add-on therapy in addition to the maximum dosage of study drugs to achieve the goal BP.

These early data in the cohort with DM in ACCOMPLISH indicate that BP control has been achieved to a greater extent than in any other previous trial, as would have been anticipated from earlier studies comparing initial monotherapy to combination therapy in patients with DM. ${ }^{13}$ Data from the ACCOMPLISH trial on BP control will provide new insights as to how to approach this growing segment of the population and further lower their cardiovascular risk.

Disclosures: The authors have relationships with the following companies: George Bakris, MD: Forest, BoehringerIngelheim, Abbott, GlaxoSmithKline, Novartis, Merck, AstraZeneca, and King. Michael Weber, MD: Forest, GlaxoSmithKline, Novartis, Bristol-Myers Squibb, Boehringer-Ingelheim, Merck, and Pfizer. Allen Hestor, PhD: Novartis. Bjorn Dahlof, MD: Merck and Novartis. Bert Pitt, MD: Pfizer, Novartis, and Merck. Ken Jamerson, MD: Novartis, Pfizer, Abbott, and Merck. Erik Velasquez, MD: Novartis. Linda StaikosByrne, PhD, and Victor Shi, PhD, are employees of Novartis.

\section{REFERENCES}

1 Fox CS, Coady S, Sorlie PD, et al. Trends in cardiovascular complications of diabetes. JAMA. 2004;292(20):2495-2499.
2 Jamerson KA, Bakris GL, Wun CC, et al. Rationale and design of the avoiding cardiovascular events through combination therapy in patients living with systolic hypertension (ACCOMPLISH) trial: the first randomized controlled trial to compare the clinical 
outcome effects of first-line combination therapies in hypertension. Am $J$ Hypertens. 2004;17(9):793-801.

3 Weber MA, Bakris GL, Dahlof B, et al. Baseline characteristics in the Avoiding Cardiovascular events through Combination therapy in Patients Living with Systolic Hypertension (ACCOMPLISH) trial: a hypertensive population at high cardiovascular risk. Blood Press. 2007;16(1):13-19.

4 Julius S, Kjeldsen SE, Weber M, et al. Outcomes in hypertensive patients at high cardiovascular risk treated with regimens based on valsartan or amlodipine: the VALUE randomised trial. Lancet. 2004;363(9426):20222031.

5 Dahlof B, Sever PS, Poulter NR, et al. Prevention of cardiovascular events with an antihypertensive regimen of amlodipine adding perindopril as required versus atenolol adding bendroflumethiazide as required, in the Anglo-Scandinavian Cardiac Outcomes Trial-Blood Pressure Lowering Arm
(ASCOT-BPLA): a multicentre randomised controlled trial. Lancet. 2005;366(9489): 895-906.

6 Major outcomes in high-risk hypertensive patients randomized to angiotensin-converting enzyme inhibitor or calcium channel blocker vs diuretic: The Antihypertensive and Lipid-Lowering Treatment to Prevent Heart Attack Trial (ALLHAT). JAMA. 2002; 288(23):2981-2997.

7 Weber MA, Julius S, Kjeldsen SE, et al. Blood pressure dependent and independent effects of antihypertensive treatment on clinical events in the VALUE Trial. Lancet. 2004; 363 (9426): 2049-2051.

8 Seventh report of the Joint National Committee on Prevention, Detection, Evaluation, and Treatment of High Blood Pressure. Hypertension. 2003;42(6):1206-1252.

9 Whelton PK, Barzilay J, Cushman WC, et al. Clinical outcomes in antihypertensive treatment of type 2 diabetes, impaired fasting glucose concentration, and normoglycemia:
Antihypertensive and Lipid-Lowering Treatment to Prevent Heart Attack Trial (ALLHAT). Arch Intern Med. 2005;165(12): 1401-1409.

10 Bakris GL. A practical approach to achieving recommended blood pressure goals in diabetic patients. Arch Intern Med. 2001;161(22): 2661-2667.

11 Mancia G, Brown M, Castaigne A, et al. Outcomes with nifedipine GITS or Co-amilozide in hypertensive diabetics and nondiabetics in Intervention as a Goal in Hypertension (INSIGHT). Hypertension. 2003;41(3):431436.

12 Jamerson K, Bakris GL, Dahlof B, et al. Exceptional early blood pressure control rates: the ACCOMPLISH trial. Blood Press. 2007; 16(2):80-86

13 Bakris GL, Weir MR. Achieving goal blood pressure in patients with type 2 diabetes: conventional versus fixed-dose combination approaches. J Clin Hypertens (Greenwich). 2003; 5(3):202-209. 